\title{
Reconstructing St. Katharinen: Archival Archaeology in Action
}

TIMOTHY J. SENIOR, University of the West of England, UK

Lying near the heart of Bremen, the St. Katharinen district is bounded by two of the city's principal medieval, and now modern, streets. As one of the earliest documented structures on the site, the Dominican monastery of St. Katharinen has come to define much of the urban fabric of the district. A substantial building complex, it served a variety of educational, commercial, military and domestic roles following the Reformation, not least housing the city's armory, library and first university. Subject to periods of extensive redevelopment, much of the complex was finally lost to the bombing raids of the Second World War and a traffic-widening scheme of the 1970s. Only a fragment now remains of the original claustral buildings, a multistory car park erected on piloti rising overhead.

Over successive redevelopments, the site was cleared with minimal archaeological investigation. Further, little scholarly research been conducted on the site to date. As such, any attempt to reconstruct the appearance of St. Katharinen is now an act of inference from archival sources: a process of archival archaeology. As part of ongoing work, I will present a new and emerging understanding of the St. Katharinen district and its urban transformation across the centuries, drawing on the most extensive body of construction, land registry, visual, textual, laser scanning and Lidar data yet assembled for the site. Whilst a project of this kind is grounded in the traditional approaches of historical architectural research, it is the capacity to assemble and analyze these diverse data sources within common digital environments that makes this conjectural reconstruction work possible.

Key words:

Medieval Architecture, Digital Reconstruction, Archival Archaeology.

SDH Reference:

Timothy J. Senior. 2018. Reconstructing St. Katharinen: Archival Archaeology in Action. SDH, 2, 2, 166-176.

DOI : $10.14434 /$ sdh.v2i2.24442

\section{INTRODUCTION}

From the Schüsselkorb, a short passageway - cut through a 1960's apartment block - leads into the Gerhard-Iverson-Hof. There, jutting out from a brutalist multistory car park, is a concrete platform raised on thin piloti over a single-story building. With its exterior surface cut back to reveal brick infill, and what appears to be exposed vaults overhead, it takes on the appearance of a oncesubterranean structure now raised above ground level: to the casual observer, its identity might be hard to discern. Post-1945 planning, favoring road expansion and the creation of open spaces, has

Author's address: Timothy J Senior, (Digital Cultures Research Centre), University of the West of England, City Campus, Watershed 1, Canon's Road, Harbourside, Bristol, BS1 5TX, UK; email: timothy.joseph.senior@googlemail.com.

(c) [2018] by the author; licensee Studies in Digital Heritage, IU, Bloomington (IN), USA. This article is an open access article distributed under the terms and conditions of the Creative Commons Attribution License (CC BY-NC). 
further disconnected this building from a legible urban context. These are the remains of the medieval Dominican monastery of St. Katharinen in Bremen, Germany (Fig. 1): a group of groundfloor rooms once belonging to its eastern claustral wing. Lying near the heart of Bremen, the 'St. Katharinen district' is bounded by two of the city's principal medieval, and now modern, streets (the Schüsselkorb and Sogestraße), the St. Katharinen monastery coming to shape much of the site's urban structure. This paper concerns the first scholarly reconstruction of this important medieval site, embedding it within the context of nearly 800 years of urban transformation. The historical overview that follows [Loschen 1864; Stein 1962; Dillschneider 1971; Tacke 2004; Senior 2014] captures key moments in that transformation, highlighting the sources that make a diachronic reconstruction of the site possible.

\subsection{The Arrival of the Dominican Order}

The Dominicans arrived in Bremen on October $9^{\text {th }} 1225$, invited by the archbishop Gerhard II von der Lippe, first to convert the Stedinger (free farmers refusing to pay tithes to the Archbishopric), then to preach against their heresy following their excommunication in 1230. Through bequests of land, the Dominicans quickly settled and became influential in the city. How soon they were able to establish a monastery is still a matter for debate. For the mendicant orders, construction was an episodic process, one dependent on the availability of funds and the needs associated with a growing religious community. A Cistercian nunnery dedicated to St. Katharinen is known to have been founded in Bremen in 1185; dissolved in 1200, this may have been the first site occupied by the Dominicans on their arrival. Certainly, a monastery dedicated to St. Katharinen at the Sogestraße was in use by 1253, with a second church (possibly an enlargement of the first) consecrated in 1285. With assets flourishing into the 13th and 14th centuries, a program of expansion was initiated: the monastery church was rebuilt into a hall format around 1400, with all three aisles raised to the same height under a single, large gabled roof.

\subsection{From Reformation to Secularization}

It is these substantive medieval structures that dictate the successive redevelopment of the site following its secularization in 1528. Passing into the custody of the city, a protestant grammar school (the Lateinschule) is founded within the eastern claustral wing, eventually becoming the city's first university (the Gymnasium Illustre). The church itself is repurposed in 1597, becoming the city's new armory, a role served until after the Napoleonic wars with its conversion into a warehouse extensively remodeled inside and out. Up until the first quarter of the nineteenth century, the former monastery would still have been legible within the city fabric. This critical early period of transformation gives rise to the first important sources for conjectural reconstruction work: visual records of these now important civic sites in their urban context, whether in the form of detailed bird's eye views or city-wide panoramas. One of the earliest such sources is a numismatic one, a commemorative medal of 1684, struck on the centenary of the Gymnasium Illustre's foundation (Fig. 1a). The early nineteenth century gave rise to, amongst others, the only known visual depiction of the armory's interior (by Jacob Ephraim Polzin), textual records of internal arrangements and furnishings, and the first accurate cross-sectional plans of domestic and commercial properties on the site. 

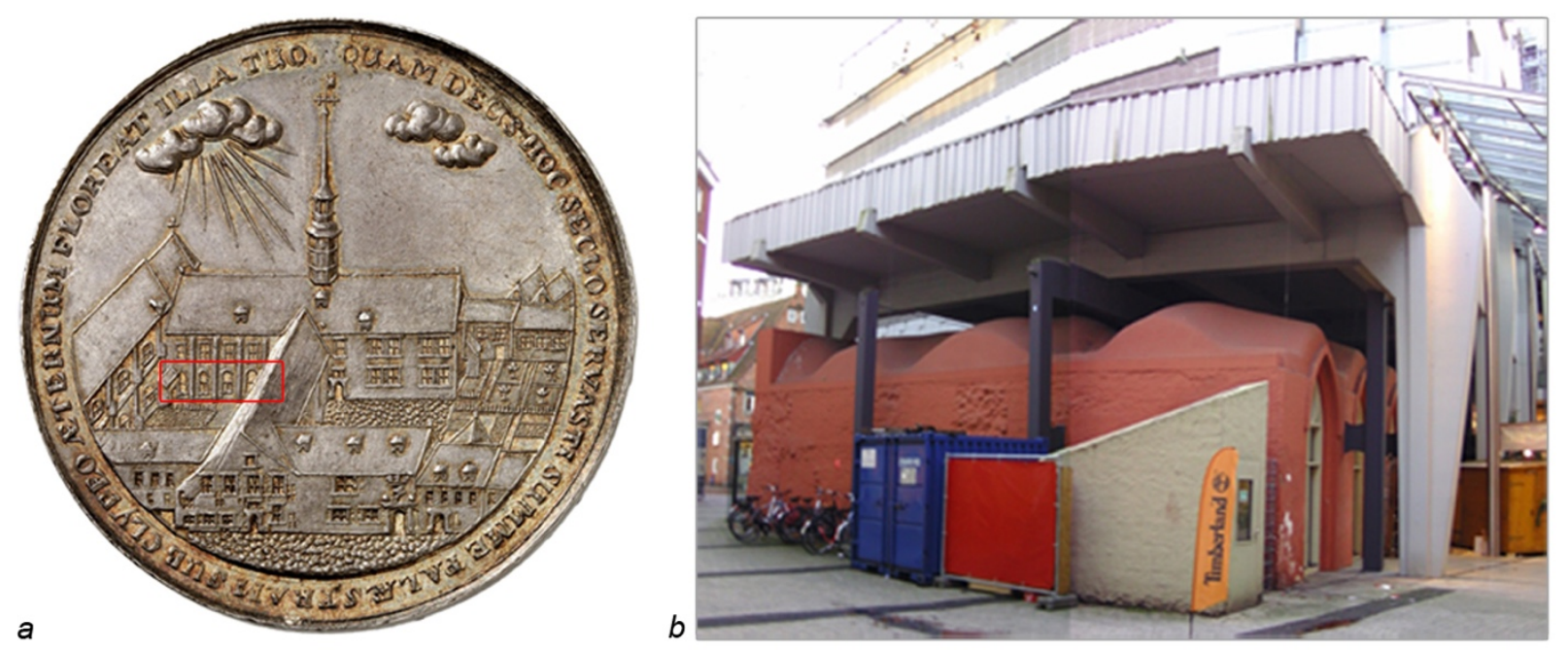

Figure 1. St. Katharinen monastery: a) commemorative silver medal for the centenary of the Gymnasium Illustre's foundation, dating from 1684. The former St. Katharinen monastery is depicted with the cloister and church left of center; the surviving fragment of the eastern claustral wing is indicated (author's collection); $b$ ) The Gerhard-Iverson-Hof today, with the Katharinen-Hochgarage and part of the former eastern claustral wing with the pointed arches of the cloister passage visible on the right (photo by the author).

\subsection{An Economic Powerhouse}

In the last half of the nineteenth century, many remaining elements of the former monastic buildings are swept away with the site's redevelopment - coinciding with Bremen's re-birth as an important mercantile center: much of the medieval walls of the former nave are lost to a new commercial building for the Meyer and Weyhausen company (1888); the domestic properties fashioned out of the former western claustral wing are either substantially altered or replaced altogether; the former eastern claustral wing (as the Realschule in der Altstadt) is extensively remodeled and modernized; and the former southern claustral wing is demolished on the departure of the city library to new and larger premises (1898). With the formalization of building records, this period provides the richest source of architectural information: individual building plans, street maps, land registry information, architectural surveys, commercial and advertising materials, and an early photographic record reveal much of this busy period of urban renewal. With most building stock in the Katharinen district either renewed or reworked, establishing the richest possible building record for this period is critical.

\subsection{Destruction and Rehabilitation}

On the nights of the 18th and 19th August 1944, the Katharinen district suffered extensive damage through an Allied bombing raid. Although little of the district survived, it was the walls of St. Katharinen that proved the most resilient. A variety of proposals for the site's rehabilitation were drawn up, the most remarkable of which must be that for the founding of the International University Bremen, drawing on the continuous, unbroken history of educational and scholarly work at the site dating back to the Faculty of Theology founded in 1450 [Kickert 2013]. With the failure of the IUB 
project, and under pressure for a traffic-widening scheme in the Schüsselkorb, heritage protection was removed from the site and the substantive remains of the choir and nave cleared in 1960. The Katharinen-Hochgarage (a multistory car park) was erected, to plans by Carsten Schröck in 1972, incorporating remains from the eastern claustral wing. As no officially recorded archaeological survey was conducted for the site (either during post-war clearance or during the construction of the multistory car park), this body of proposals for redevelopment (and the surveying work carried out for them) form a lynch pin of the modern building record. With its extensive subterranean parking level, there is also little left in the vicinity of the Katharinen-Hochgarage to excavate today, and questions have been raised in identifying where sites of potential interest for archaeological work might lie. Further, with the extensive erasure of the Katharinen district's pre-war condition and its subsequent urban transformation (with only five buildings in an area of around 9,500 $\mathrm{m}^{2}$ retained to the present day), establishing the precise correspondence between pre- and post-war building plots can be a challenge. Nonetheless, detailed cadastral and Lidar data are now available describing the site in its current state, supplemented by 3D laser-scan data of the remaining medieval structures (see methods).

\section{A CASE OF ARCHIVAL ARCHAEOLOGY}

Two different proposals for a reconstructed plan of the St. Katharinen monastery were made after the second world war, referencing earlier architectural surveys and structural elements uncovered (but not officially recorded) during post-war site clearance. (Unpublished plans by Gebhardt from 1949, Fricke from 1950, and a survey by Schlüter from 1932 - all held in the archive of the Bremen State Office for the Protection of Historical Monuments). Notwithstanding the still-extant rooms of the former eastern claustral wing, no two components of these reconstructions are alike. In its present state, and with the promise of significant archaeological discoveries low, the focus must turn to the archival record. Although the site has never enjoyed much scholarly attention, its re-purposing under a multiplicity of ownerships has resulted in a rich body of archival sources. This research is, as such, a form of archival archaeology, a process of working back from the site's current state (the most complete for measurement and description) through iterations of the site towards its earliest origins. At each stage, an increasing number of inferences are made as source availability diminishes and issues over source interpretation arise. This work in turn generates predictions that might prompt the reappraisal of existing sources or the targeted search for new ones. Subject to a degree of unpredictability associated with the uncovering of sources (and the impact they may have on understanding the site), this is an ongoing process of conceptual modeling through source interpretation and re-interpretation. This diachronic approach aims to build a picture not only of the St. Katharinen monastery's development over time, but to situate that knowledge firmly in a forwardlooking orientation, in order to ask: how did we arrive at the urban structure of today from the medieval world?

\subsection{Sources and Methods}

To establish the widest possible building record for the Katharinen district, archival sources have been drawn from, amongst others, the State Archives of Bremen and Lower Saxony, the Bremen State Office for the Protection of Historical Monuments, the Office for Archaeology, and the Office for Land 
registration \& Geo-information, the Bremen Building Authority, the Bremen State Institute for Schools, the Focke Museum, and the Archives of Radio Bremen (Bremen's public radio and television broadcaster). In addition, mobile 3D laser mapping of the site was conducted in collaboration with Professor Dr. Andreas Nüchter (Universität Würzburg, Germany). A variety of digital tools have been used to process data and conduct analyses, including QGIS for geo-referencing work, '3D Toolkit' (Andreas Nüchter) for processing 3D point clouds, Google Sketchup for rudimentary 3D modeling, and Sketchfab for demonstrating work in progress. Additional tools such as the orthogonalization software (RDF) (Università Iuav di Venezia, CIRCE Photogrammetry Lab), Autocad, and Photoshop have been used in the comparison and analysis of digital images.

In QGIS, 27 historic cadastral and city maps for the Katharinen district (1:100 through 1:1000) were manually geo-referenced with ground control points (GCPs) against 2017 cadastral data (accuracy \pm 10cm; Bremen State office for Land Registration) and laser scan data relating to the existing medieval structures. Thin plate spline transformations with nearest neighbor resampling, and Helmert transformations with linear resampling were used for this process of assessing map fit. A second step is the placement of individual building plans to locate fine grained structural features within the site (such as individual walls), using the degree of internal plan consistency (e.g. alignment between drawn and written measurements) and their fit to the geo-referenced district map as a guide to the reliability of feature placement. Photographic and drawn representations permit higher levels of detailing (including 3D spatial information) to be assessed.

GCPs were identified through a reconstructed history of each building plot in the Katharinen district (assembled through plans, photos, and building records). Given the degree of site transformation over the decades, these GCPs sit within a hierarchy: 1) at the top are those extant architectural features found both in historical maps and the 2017 reference data; 2) key boundary elements preserved across periods in the face of building substance alteration or renewal; 3 ) features (no longer extant) that persist across historical maps and whose position can be cross-validated across multiple sources at different scales; 4 ) those features that derive from the most reliable historical maps (those requiring the least transformation) in the absence of all other means of validating feature location. For each historical map, this leads to a spatial probability matrix describing the reliability of transformations made in a given area. The minimal number of GCPs is sought to bring historical maps into alignment.

\section{EMERGING INSIGHTS}

An ongoing research project, the following four examples explore some of the findings now beginning to emerge.

1. Through the process described, a large-grain, diachronic reconstruction of the Katharinen district is now possible, one subject to ongoing refinement (Fig. 2a-d). Within this, a threedimensional model is now emerging of putative building elements belonging to the former monastic site and the as yet unconfirmed structural relationships they imply. Cellar spaces (often more robust to re-developments above ground) are proving useful, helping to generate sites of interest for future archaeological work and investigation. The body of material being developed is also enabling an historical account of earlier 'reconstruction activities' to be 
pieced together: this includes identifying which sources may have been relied on previously (and so correctly oriented or misdirected work), and pinpointing where earlier reconstructions and the current body of evidence deviate, indicating reconstructed features that may be either conjectural in nature or point towards sources that may be missing or as yet unidentified.

2. This research is beginning to reveal fine-grained chronological elements in the construction of St. Katharinen, for example, in relation to its re-construction as a hall church. A substantial fragment of the medieval northern nave wall was retained across successive redevelopments of the site up until 1961; within the building record assembled, a handful of photographs and some rare film footage from its final demolition have been identified, shedding light on its construction history. These photographs have been digitally orthogonalized and scaled, allowing regions of the former nave wall to be dated according to characteristics such as brick size and bond pattern. A clear boundary, at window sill level, divides large, characteristically late-medieval brickwork in monk bond from smaller bricks below arranged in stretcher formation with interspersed headers; film footage of a mechanical digger demolishing this lower stretch of wall substantiates the interpretation as a single brick layer with rubble-infilling - a characteristic of later 12th century building practices in the region (J.C. Holst 2017, personal communication, 30 July). Together, these point towards the raising of existing nave walls into the final hall church formation in the late medieval period, but also the tentative indication of a pre-Dominican structure on that site. Further examination should help date this first phase of construction (particularly in relation to other examples of possible late Romanesque work found elsewhere in the building record). Additional insights include the accurate localization of buttresses in relation to the northern nave wall and its window openings - captured as regularly spaced 'negative' elements within properties built up against the church's walls.

3. An ongoing challenge in the reconstruction process concerns the shape and orientation of the church's west front. The incomplete, but also highly ambiguous, building record leads to a number of possible interpretations. One is an unusual 'kinked' façade (perpendicular to the nave body in the south but angled at 14 degrees off-perpendicular in the north) with pairs of internal columns oriented initially in a similar fashion in the west but brought closer to the perpendicular towards the nave's east end (Fig. 2f). Here, the interpretation of graded shading on a detailed depiction of the west front (from Daniel Heinbach in 1734) as indicating a change in façade orientation, is highly significant. Such structural adaptations to an irregularly shaped plot of land were not uncommon amongst the Mendicant orders, reflecting the episodic expansion of property and buildings, as well as the tension between a site's physical constraints and the need to make best use of the land available. Superficially, a similar 'solution' can be found at the Franciscan church of St. Matthieu in Colmar, albeit in relation to an un-vaulted, basilica form. Understanding the decisions behind, and structural constraints of, a particular approach can reveal insight into Mendicant building culture of the medieval period. 

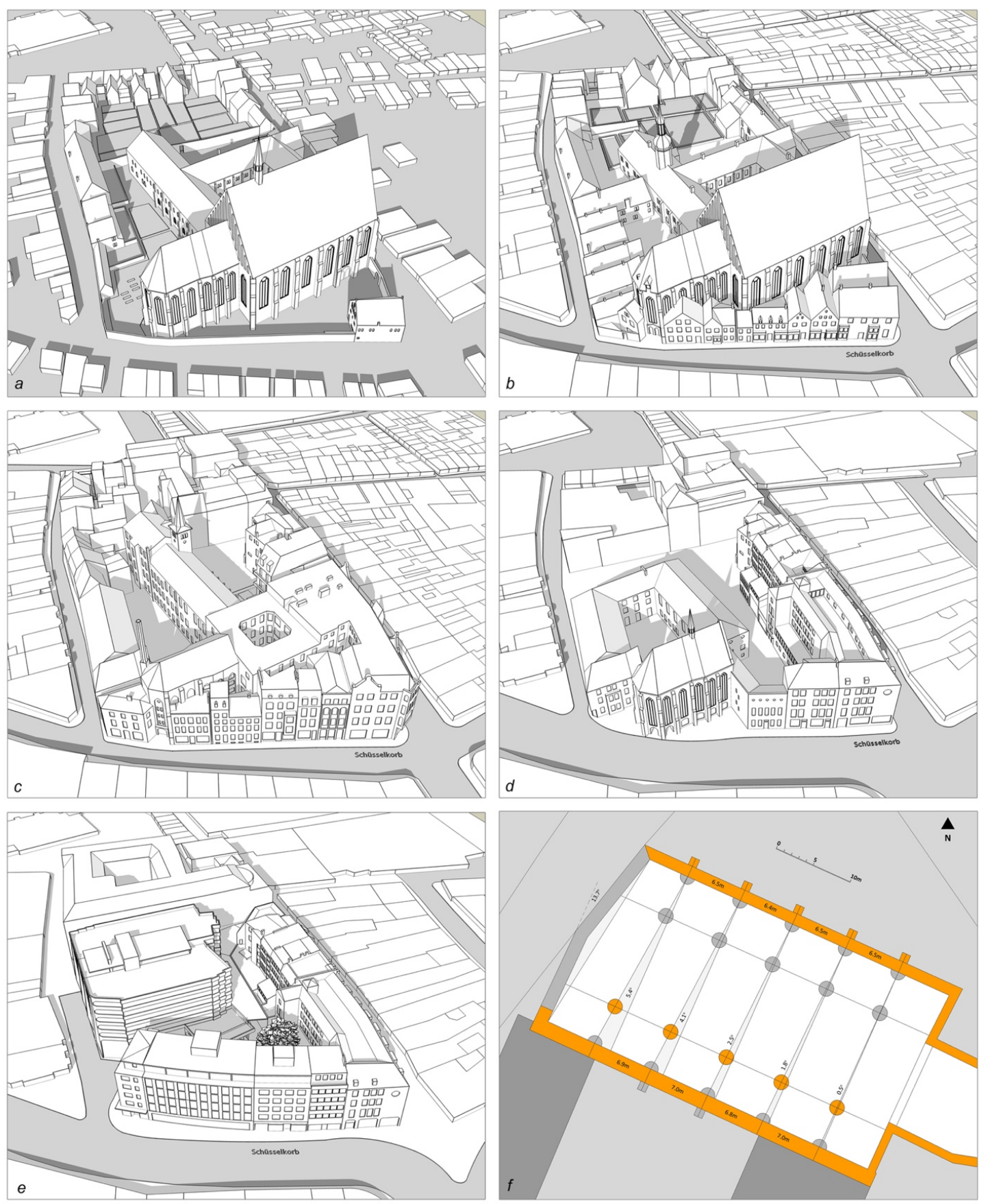

Figure 2. The Katharinen district in different phases of development [Senior 2014]: a) circa 1450; b) circa 1750; c) circa 1930; d) circa 1950 when the proposed development of the International University Bremen took place; e) the site today, with the Katharinen-Hochgarage centre-left; f) one proposal for the west front of St. Katharinen (orange - structures interpreted from the architectural record; light grey - hypothesized structures). 
The interpretation presented for St. Katharinen implies a strategy initiated at the rebuilding of the church in Hall form, one that might maximize the space attained, whilst permitting an elaborate vaulting system that could harmonize across this unconventional space. A structural simulation of the statics involved may help in discerning between the validity of different interpretations so far generated.

4. A final example of emerging insights concerns the piecing together of different archival sources within a modeling environment to spatially locate known, but no longer extant, architectural features. During demolition of the eastern claustral wing in 1949, a single, painted medieval window jamb was uncovered within an exterior wall. Archival sources suggest that the costs of conserving and safely removing the window jamb were considered prohibitive; a decision to document but then clear the site was made. The exact location of this window jamb, however, was never recorded. Re-establishing its location is not only a key part of the reconstruction process, but also may generate hypotheses for the design and location of similar window openings elsewhere.
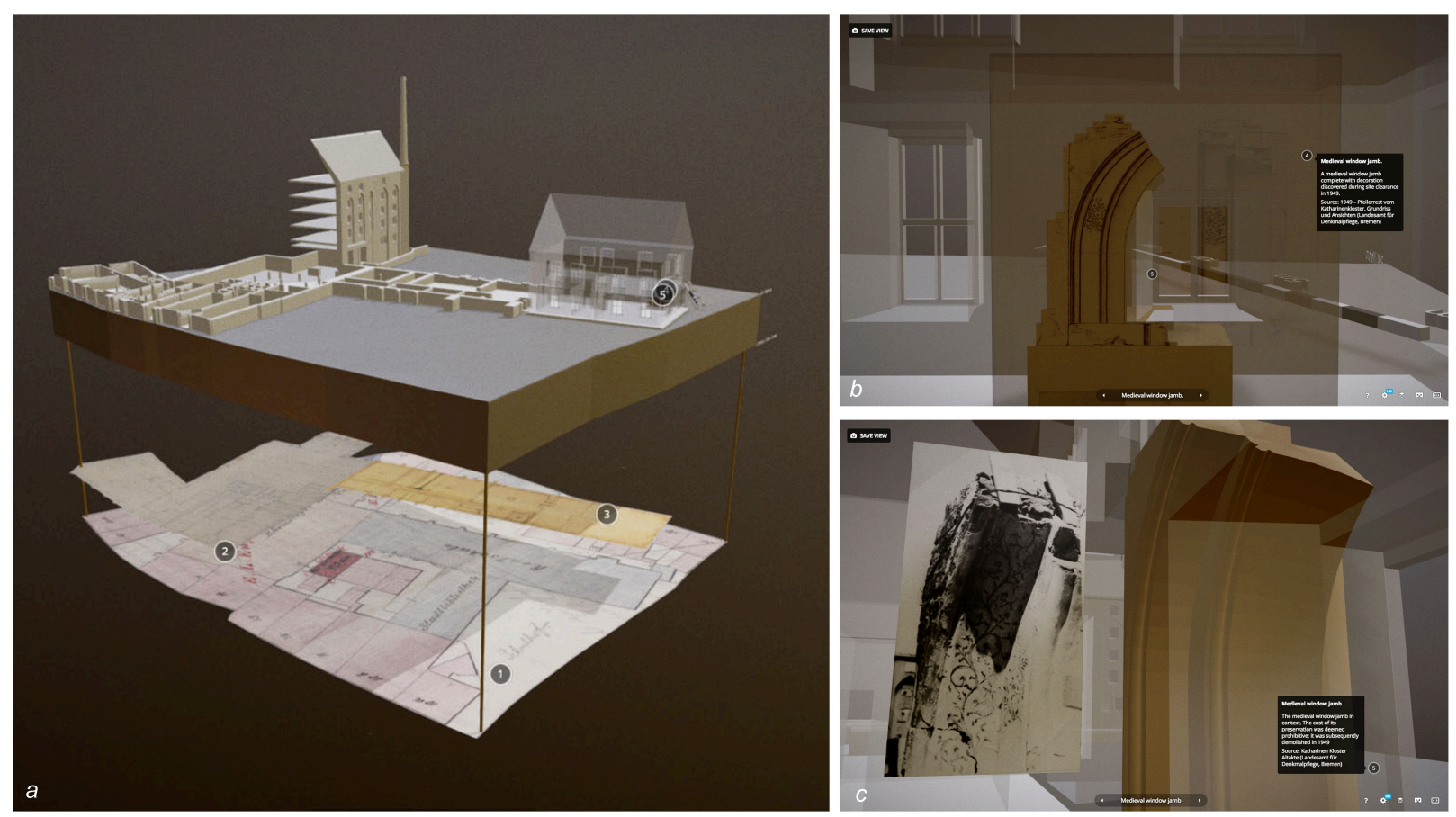

Figure 3. One hypothesis for the position of a now-lost medieval window jamb uncovered in the former eastern claustral wing of the St. Katharinen monastery during site clearance in 1949 - as modeled in Sketchfab: a) A partial model of the site prior to 1944 juxtaposing architectural features and historical plans. The former choir of St Katharinen, with floor-stack inserted, is shown top left. Five navigable locations are indicated; b) Location 4 in the model, showing hand-drawn documentation of the window jamb fragment on a 2D plane positioned in front of that same fragment modeled in situ; c) Location 5 with a line-of-sight that matches the modeled feature (with the choir in the background) to a 1949 photograph of the site. 
The use of this building as a secular educational establishment from the Reformation up to the second world war has resulted in a detailed and diachronic building record, one that captures the modernization and reorganization of classroom layouts. This includes alterations made to the position of window openings, so helping identify those locations where a medieval window jamb may have been retained. 3D modeling environments allow these different positions to be assessed and refined, also in relation to 'line-of-sight' comparisons made with the photographic record of the window jamb and its surroundings. Making these putative relationships (and the sources that shape them) visible and put into the actual context is an important part of this research process; the capacity to juxtapose 3D models and archival images projected onto situated planes is helpful in this regard (Fig. 3).

\subsection{Observations on the Digital in Architectural History}

At the heart of this research project is the need to assemble a considerable variety of data sources within common digital environments, whether for storage, comparison, analysis, or expression: a statement of how digital tools enhance the degree of control in any scholarly reconstruction activity. (Whether geo-referencing historical maps within a single frame of reference, orthogonalizing and taking measurements from historical photographic records, or rapidly and iteratively modeling three dimensional structures, and so on.) This includes a recognition of the role digital tools play in increasing access to many data sources (and types of data sources) and bringing geographicallydispersed expertise together into the conversation. Whilst traditional, disciplinary practices in the study of architectural history are still at the core of many of these activities, the advantages gained in their coordination and execution cannot be under-estimated. Advances in how source materials can be flexibly brought together within digital environments, or the ease of moving between geographic, modeling and archival contexts, will only push further the insights that can be gained in this field. Particularly important for the current project will be the ability to make visible the complex decision-making processes that underlie any speculative reconstruction process (functionalities of the kind seen in Sketchfab).

Beyond the tools themselves, it is the close alignment between digital innovation and the changing nature of cross-disciplinary collaboration that underlies an important shift in the study of architectural history, for example through new attitudes to disciplinary practice and an openness to perspectives from outside of traditional spheres of training, or a recognition that digital tools can equip more people to ask high-level questions of their own lived environments according to their own interests. In this sense, what is remarkable about advances in digital tools is their influence over who gets to contribute to our understanding of built heritage. This is, however, more than just a question of participation: it is the use of digital tools to bring historic sites into contemporary and legible forms - forms that parallel those of our every-day, wider engagement with the world - that can act as a powerful generator of insight into our built heritage. The Katharinen district will continue to change, and undoubtedly in ways shaped by its medieval past. For this author, whose research concerns not architectural and urban history but new models of cross-disciplinary knowledge exchange, it is an interest in engaging with the architecture of our past as a function of contemporary urban issues (and a projection to future needs) that informs the long-term aspirations of this work. An early project that emerged out of this research into the St. Katharinen district was an 
undergraduate course taught simultaneously at Jacobs University (Bremen, Germany) and Duke University (Durham, USA) which aimed to engage students with their own historical material culture and built environment in this way [Senior et al., 2013].

Brought together, a third key point emerges. The digital heritage field is characterized by an enormous range of disciplines (and increasingly creative and cultural industry partners), each with perspectives on innovation that are particular to them. What a conference like CHNT reveals is an expansion, not a reduction, in what is being asked of digital practices (across levels of data complexity, R\&D practices, public interactivity and accessibility, cross-platform compatibility, production-values, project legacy, and so on). The proliferation of digital tools (and their future projected capacities), parallels these demands and exists in a mutually reinforcing relationship. This is a complexity we should celebrate - a non-centralized digital innovation ecosystem that generates a steady stream of new tools and ideas, driving us to ask questions of our research methods and collaborative models. Drawing on the Katharinen district project for a perspective, the capacity to work across multiple geographical, modeling and archival environments through free, open source, bespoke, and affordable digital software is at a very high level today; a state that can only strengthen the chance of bringing sites like the Katharinen district to light - seemingly invisible to the casual observer, but with a story that can situate where we are today and so inform where we might wish to go next.

\section{ACKNOWLEDGEMENTS}

The author gratefully acknowledges Prof. Dr. Andreas Nüchter (Universität Würzburg) for the 3D environment mapping data, the IS+S and Wired! teams at Duke University (including Professor Caroline Bruzelius, Dr. Edward Triplett, and Dr. Victoria Szabo) for inspiration, scholarly guidance and technological assistance, and the ongoing support of Uwe Schwartz at the Bremen Landesamt für Denkmalpflege.

\section{REFERENCES}

Caroline Bruzelius. 2014. Preaching, Building, and Burying: Friars in the Medieval City. Yale University Press, New Haven.

Karl Dillschneider. 1971. Aus Geschichte und Baugeschichte des Dominikanerklosters, der Klosterkirche St. Katharinen und des Beginenhauses in Bremen. In Der Aufbau: Bürger und Stadt. Bremen: Heft 3, 94-100.

Germaine Kickert. 2013. The Plan of an International University Bremen after WW2 \& Why it Failed, B.A. Thesis. Jacobs University, Bremen, Germany.

Simon Loschen. 1864. Über mittelalterliche Backesteinarchitektur in Bremen, insbesondere am Katharinenkloster. In Bremisches Jahrbuch. Staatsarchiv Bremen, Bremen: vol. 1, 309-314.

Rudolf Stein. 1962. Romanische, Gotische und Renaissance-Baukunst in Bremen. Hauschild-Verlag, Bremen, 186-196.

Timothy J. Senior, Florian Wiencek, and Victoria Szabo. 2013. Digital Cities: A Collaborative Engagement with Urban Heritage. In Proceedings of the Digital Heritage International Congress 2013. IEEE, 349-352. 10.1109/DigitalHeritage.2013.6744778. 
Timothy J. Senior. 2014. The Dominican Friars in Bremen: Shaping a Cultural and Urban Landscape. In Denkmalpflege in Bremen. Temmen: Bremen, (11) 97-109.

Wilhelm Tacke. 2004. Das Dominikanerkloster St Katharinen - In Klöster in Bremen: Über 800

Jahre Konfessionsgeschichte der Freien Hansestadt Bremen. Temmen, Bremen, 21-33.

Received September 2018; revised October 2018; accepted December 2018. 